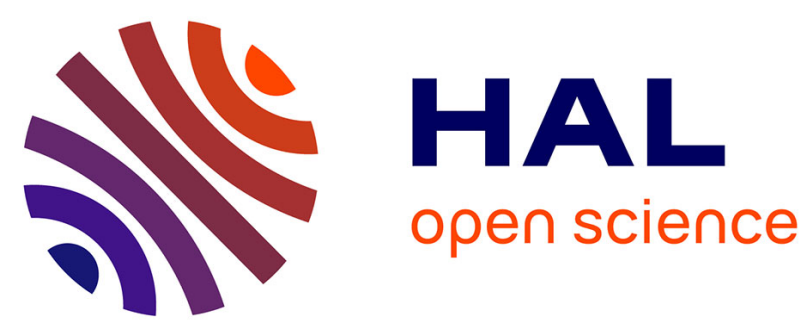

\title{
Rapid dynamic R1/R2*/temperature assessment: a method with potential for monitoring drug delivery
}

Cyril Lorenzato, Chris Oerlemans, Alexandru Cernicanu, Mario Ries, Baudouin Denis de Senneville, Chrit Moonen, Clemens Bos

\section{- To cite this version:}

Cyril Lorenzato, Chris Oerlemans, Alexandru Cernicanu, Mario Ries, Baudouin Denis de Senneville, et al.. Rapid dynamic R1/R2*/temperature assessment: a method with potential for monitoring drug delivery. NMR in Biomedicine, 2014, 27 (11), pp.1267-1274. 10.1002/nbm.3182 . hal-01578215

\section{HAL Id: hal-01578215 \\ https://hal.science/hal-01578215}

Submitted on 29 Aug 2017

HAL is a multi-disciplinary open access archive for the deposit and dissemination of scientific research documents, whether they are published or not. The documents may come from teaching and research institutions in France or abroad, or from public or private research centers.
L'archive ouverte pluridisciplinaire $\mathbf{H A L}$, est destinée au dépôt et à la diffusion de documents scientifiques de niveau recherche, publiés ou non, émanant des établissements d'enseignement et de recherche français ou étrangers, des laboratoires publics ou privés. 


\section{Rapid Dynamic Temperature/ $\mathbf{R}_{1} / \mathbf{R}_{2}{ }^{*}$ Assessment: A Method With Potential For Monitoring Drug Delivery.}

Cyril Lorenzato ${ }^{1}$, Chris Oerlemans ${ }^{1}$, Alexandru Cernicanu ${ }^{2}$, Mario Ries ${ }^{1}$, Baudouin Denis de Senneville ${ }^{1,3}$, Chrit Moonen ${ }^{1}$, Clemens Bos ${ }^{1}$.

${ }^{1}$ University Medical Center Utrecht, Department of Radiology, Imaging Division, Heidelberglaan 100, 3584 CX Utrecht, The Netherlands.

${ }^{2}$ Toshiba Medical Systems Europe, Zoetermeer, The Netherlands

${ }^{3}$ Institut de Mathématiques de Bordeaux, UMR 5251 CNRS/Université Bordeaux 1/INRIA, F-33400 Talence, France.

Short Title:

Rapid Dynamic Temperature $/ \mathrm{R}_{1} / \mathrm{R}_{2}{ }^{*}$ Monitoring

Keywords:

Magnetic resonance imaging (MRI); apparent proton density (APD); drug delivery systems (DDS); thermosensitive liposome (TSL); relaxometry, $\mathrm{R}_{1}, \mathrm{R}_{2}{ }^{*}$; focused ultrasound; High Intensity focused ultrasound (HIFU)

Word Count:

$\mathbf{5 2 0 1}$ words in total $(4379+822$ from the references $)$

Sponsors:

European Research Council, project number 268905 "Sound Pharma".

Corresponding Author:

Clemens Bos, Sr. Scientist | Imaging Division | University Medical Center Utrecht Room Q 0S.208 | Mail address: Q 00.118 | Postbus 85500 |3508 GA Utrecht $\mathrm{T}+31$ (0)88 7550279 |F +31 (0)88 7555850 | E-mail: $\underline{\text { C.Bos@ @umcutrecht.nl }}$ 


\section{GRAPHICAL ABSTRACT}

This method consist in mapping, near-real-time ( $<6 \mathrm{~s}$ for complete mapping), both $\mathrm{R}_{1}, \mathrm{R}_{2}{ }^{*}$ and the temperature variation based on a dynamic multiecho spoiled gradient-echo data. The results suggest that it can be used to monitor the release of a paramagnetic contrast agent from thermosensitive liposomes and it has potential for use in image-guided drug delivery studies. 


\section{ABSTRACT}

Local drug delivery by hyperthermia-induced drug release from thermosensitive liposomes (TSL) may reduce systemic toxicity of chemotherapy, while maintaining or increasing its efficacy. Relaxivity contrast agents can be co-encapsulated with the drug to allow visualizing the presence of liposomes, by means of $\mathrm{R}_{2}{ }^{*}$, as well as the co-release of the contrast agent and the drug, by means of $\mathrm{R}_{1}$, upon heating. Here, the mathematical method used to extract both $\mathrm{R}_{2}{ }^{*}$ and $\mathrm{R}_{1}$ form a fast dynamic multiecho spoiled gradient-echo (MESPGR) is presented and analyzed. Finally this method is used for monitoring such release events.

$\mathrm{R}_{2}{ }^{*}$ was obtained from a fit to the the ME-SPGR data. Absolute $\mathrm{R}_{1}$ was calculated from the signal magnitude changes corrected for the apparent proton density changes and a baseline Look-Locker $\mathrm{R}_{1}$ map.

The method was used nearly homogenous heating using a water bath and local focused ultrasound heating of muscle tissue and to visualize the release of a Gd-chelate from TSLs in vitro. $\mathrm{R}_{2}{ }^{*}, \mathrm{R}_{1}$ and temperature maps were measured with a 5 seconds temporal resolution. Both $\mathrm{R}_{2}{ }^{*}$ and $\mathrm{R}_{1}$ measured were found to change with temperature.

The dynamic $R_{1}$ measurements after heating agreed with the Look-Locker $R_{1}$ values, if changes of equilibrium magnetization with temperature were considered. Release of Gd from TSLs was detected by an $\mathrm{R}_{1}$ increase near the phase transition temperature, as well as a shallow $\mathrm{R}_{2}{ }^{*}$ increase.

Simultaneous temperature, $\mathrm{R}_{2}{ }^{*}$ and $\mathrm{R}_{1}$ mapping is feasible in real time and has potential for use in image-guided drug delivery studies. 


\section{INTRODUCTION}

Undesired side effects associated with chemotherapeutic drugs can be substantial. Therefore, there is a need for drug delivery systems (DDS) that may favorably alter the pharmacokinetics of the drug (1) and reduce the toxic side effects as observed with systemic chemotherapy. Taking advantage of the ability of DDS to carry both imaging and therapeutic agents, detectable drug carriers have been prepared that allow imaging the drug distribution non-invasively (2-4). In this context MRI is a potentially interesting modality: DDS that behave as temperature-sensitive switchable MR contrast agents have been prepared, and would allow monitoring their availability $(5,6)$ and their release process $(7-$ 9) based on MR-relaxometry measurement of the transversal relaxation rates $\left(R_{2}, R_{2}{ }^{*}\right)$ and the longitudinal relaxation rates $\left(\mathrm{R}_{1}\right)$, respectively.

In addition, MRI can non-invasively provide temperature maps, e.g. using the Proton Resonance Frequency Shift method (10), and can thus be used for continuous guidance of the hyperthermia procedure that triggers drug release (11). One of the techniques to achieve local hyperthermia is High Intensity Focused Ultrasound (HIFU), which has been successfully integrated with MRI, such that MR thermometry controls the HIFU heating (12). Therefore, it would be of great value for the development of these image guided drug delivery techniques to have access to quantitative relaxometry $(7,13)$ and temperature at the same time.

In this work, a fast dynamic MRI method to simultaneously acquire PRF-based thermometry data, $\mathrm{R}_{2}{ }^{*}$ and $\mathrm{R}_{1}$ maps using a dynamic multi gradient echo sequence is presented. To assess the feasibility of this approach, the signal change in response to 
changes of $R_{1}$ and the influence of the variance of transverse relaxation rate $R_{2}{ }^{*}$ estimation on the quantification of the longitudinal relaxation rate $\mathrm{R}_{1}$ were analyzed. Subsequently the method was validated in vitro in a porcine muscle sample, initially using a water bath for heating and then applying local heating using MR-guided HIFU. Finally, the method was used to monitor the release of a paramagnetic contrast agent from thermosensitive liposomes (TSL). The method is a step towards monitoring two important phases of imageguided drug delivery: availability of nanocarriers and release in the target tissue. 


\section{METHODS}

\section{Data Acquisition}

Real time mapping of relaxation times $\mathrm{R}_{1}$ and $\mathrm{R}_{2}{ }^{*}$ was based on a multi-echo RFspoiled gradient echo sequence (ME-SPGR). For this sequence, the signal is given by,

$$
\mathrm{S}_{\mathrm{n}}(\mathrm{TE})=\sin (\alpha) \cdot \mathrm{M}_{0} \cdot \mathrm{e}^{-\mathrm{TE} \cdot \mathrm{R}_{2}^{*}} \cdot\left|\operatorname{sinc}\left(\frac{\gamma \Delta \mathrm{B}_{0} / \mathrm{dz}}{2 \mathrm{TE}}\right)\right| \cdot \frac{\left(1-\mathrm{e}^{-\mathrm{TR} \cdot \mathbf{R}_{1}}\right)}{\left(1-\cos (\alpha) \mathrm{e}^{-\mathrm{TR} \cdot \mathbf{R}_{\mathbf{1}}}\right)},
$$

where $S_{n}(T E)$ is the signal of dynamic $n$ for a given echo time TE, $\alpha$ is the flip angle, $M_{0}$ is the nuclear magnetization which can be thought of as an apparent proton density (APD), $\gamma$ the gyromagnetic ratio, and TR the repetition time. For slice selective sequences, the sincterm reflects the effect of the macroscopic main field inhomogeneity, which is assumed for these anisotropic voxels to be dominated by the field variation $\Delta \mathrm{B}_{0} / \mathrm{dz}$ in slice direction (14).

With a fixed TR and $\alpha$, the ME-SPGR does not allow quantifying $\mathrm{R}_{1}$. Instead, a baseline $\mathrm{R}_{1}$ map is measured first, which is then updated based on the signal changes for each MESPGR dynamic. In this study, the initial $\mathrm{R}_{1}$ map was measured using a Look-Locker acquisition (15) (resolution $=1 \times 1 \times 3 \mathrm{~mm}^{3} ; \mathrm{FOV}=128 \mathrm{~mm} ; \mathrm{TR}=4 \mathrm{~s} ; \alpha=5^{\circ}$; Images were acquired for 30 time points after the inversion, starting at $30 \mathrm{~ms}$ with $60 \mathrm{~ms}$ intervals; TFE factor $=5$ ).

Subsequently, a $\mathrm{B}_{0}$ map was estimated from the phase images of a multislice MESPGR scan without slice gap. Phase evolution from echo to echo was limited to be smaller than $\alpha$ ans echoes with signal magnitude below than $10 \%$ of the first echo were excluded as proposed in (14). The resonance frequency was then obtained by calculating the slope of a 
linear fit to the signal phase as a function of echo time. Next, A map of the local gradient field $\Delta \mathrm{B}_{0} / \mathrm{dz}$ was derived from a linear fit to the frequency values in the slice direction.

Finally, the central slice of the ME-SPGR was dynamically acquired to map temperature, $\mathrm{R}_{2}{ }^{*}$ and $\mathrm{R}_{1}$ over time. All ME-SPGR images were acquired using the same parameters $\left(\mathrm{TR} / \mathrm{TE}_{1} / \Delta \mathrm{TE}=50 / 4.6 / 4.6 \mathrm{~ms} ; \alpha=25^{\circ} ; 10\right.$ echoes; fly-back; voxel size = $1 \times 1 \times 3 \mathrm{~mm}^{3} ;$ scan time $=5.6$ seconds $/$ slice $)$.

All calculations were performed on a voxel-by-voxel basis using custom scripts written in IDL, (Exelis, Boulder, CO, USA) and in $\mathrm{C}^{++}$for the Levenberg-Marquardt algorithm. All data was acquired on a 1.5 T MR system (Philips Healthcare, Best, The Netherlands).

\section{Data analysis and Processing}

Dynamic $R_{2}^{*}$ mapping

$\mathrm{R}_{2}{ }^{*}$ maps were calculated from the multi-echo data using Eq.[1], assuming fixed $\alpha$, $\mathrm{M}_{0}$ and $\mathrm{R}_{1}$ values:

$$
\left.\mathrm{S}\left(\mathrm{TE}, \Delta \mathrm{B}_{0} / \mathrm{dz}\right)=\mathrm{S}_{0} \mathrm{e}^{-\mathrm{TE} \cdot \mathrm{R}_{2}^{*}} \cdot \mid \operatorname{sinc}\left(\gamma \cdot\left(\Delta \mathrm{B}_{0} / \mathrm{dz}\right) / 2 . \mathrm{TE}\right)\right) \mid
$$

Here, $\mathrm{S}_{0}$ is the signal when TE approaches 0 . Three ways of handling $\Delta \mathrm{B}_{0} / \mathrm{dz}$ compensation for fitting $\mathrm{R}_{2}{ }^{*}$ were evaluated: 1) $\Delta \mathrm{B}_{0} / \mathrm{dz}$ is assumed to be zero and $\mathrm{R}_{2}{ }^{*}$ can be extracted from a mono-exponential Levenberg-Marquardt (LM) fit; 2) $\Delta \mathrm{B}_{0} / \mathrm{dz}$ is assumed to be constant; it is measured once using the multislice ME-SPGR phase maps and then the sinc term from the Eq.[2] is calculated and included in the $\mathrm{R}_{2}{ }^{*}$ fitting process; 3) $\Delta \mathrm{B}_{0} / \mathrm{dz}$ is updated for each dynamic using the method described by Schaeffter et al. (14). In this last case, the measured $\Delta \mathrm{B}_{0} / \mathrm{dz}$ map was used as an initial value for an iterative algorithm that 
updates the $\Delta \mathrm{B}_{0} / \mathrm{dz}$ map from frame to frame. Briefly, the magnitude intensity for each echo is corrected (divided) by the corresponding absolute sinus cardinal term calculated from the first $\Delta \mathrm{B}_{0} / \mathrm{dz}$ map. Then a first $\mathrm{R}_{2}{ }^{*}$ estimate is obtained by fitting the $\Delta \mathrm{B}_{0} / \mathrm{dz}$ corrected signal to the remaining mono-exponential decay term in equation [2]. Finally, based on this first $\mathrm{R}_{2}{ }^{*}$ estimate, $\Delta \mathrm{B}_{0} / \mathrm{dz}$ is adjusted and the process is iterated to minimize the squared error in [2].

Dynamic $R_{1}$ mapping

The implemented method estimates a change in $\mathrm{R}_{1}$ based on the signal magnitude change under SPGR conditions. To allow measuring absolute $\mathrm{R}_{1}$ values, an initial $\mathrm{R}_{1}$ map is needed, which was calculated from the Look-Locker data (15).

$\mathrm{R}_{1}$ change $\left(\Delta \mathrm{R}_{1}\right)$ over time was calculated using the signal change at the shortest TE. For that purpose the signal from each new dynamic $S_{n}$ is divided by the signal of the reference dynamic $\mathrm{S}_{0}$.

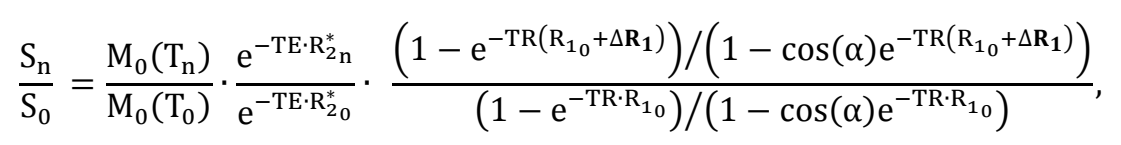

From Eq.[3] it is apparent that for quantitative $\mathrm{R}_{1}$ measurements, influence of temperature change and $\mathrm{R}_{2}{ }^{*}$ change should be considered. The APD is proportional to the equilibrium nuclear magnetization $\mathrm{M}_{0}$, with $\mathrm{M}_{0}(\mathrm{~T})=\mathrm{N} \gamma^{2} \mathrm{~h}^{2} \mathrm{I}(\mathrm{I}+1) \mathrm{H}_{0} / 3 \kappa \mathrm{T}$, where $\kappa$ is Boltzmann's constant, $\mathrm{N}$ is the number of nuclear spins per unit volume, and $\mathrm{T}$ is the absolute temperature. Thus, $\mathrm{M}_{0}$ is inversely proportional to the temperature, with a resulting signal change of approximately $0.29 \% /{ }^{\circ} \mathrm{C}$ in the experimental range of 20 to $60{ }^{\circ} \mathrm{C}$ (16).Hence, the APD influence on the signal ratio can be easily compensated if the relative temperature 
variation is known. The second factor in Eq.[3] is related to $\mathrm{R}_{2}{ }^{*}$ and can be calculated from the dynamic $\mathrm{R}_{2}{ }^{*}$ mapping. The $\Delta \mathrm{R}_{1}$ is then determined numerically, in an iterative fashion, from Eq.[3], which can be rewritten as follows after compensation for $\mathrm{M}_{0}$ and $\mathrm{R}_{2}{ }^{*}$ :

$$
\frac{\mathrm{S}_{\mathrm{n}}}{\mathrm{S}_{0}}\left(\mathrm{M}_{0}, R_{2}^{*}\right)=\frac{\left(1-\mathrm{e}^{-\mathrm{TR}\left(\mathrm{R}_{1_{0}}+\Delta \mathbf{R}_{1}\right)}\right) /\left(1-\cos (\alpha) \mathrm{e}^{-\mathrm{TR}\left(\mathrm{R}_{10}+\Delta \mathbf{R}_{1}\right)}\right)}{\left(1-\mathrm{e}^{-\mathrm{TR} \cdot \mathrm{R}_{10}}\right) /\left(1-\cos (\alpha) \mathrm{e}^{-\mathrm{TR} \cdot \mathrm{R}_{10}}\right)}
$$

Using $\mathrm{R}_{10}$ as obtained from the Look Locker method, this provides an $\mathrm{R} 1$ value at every time point.

Proton resonance frequency based thermometry

PRF shift was calculated using the unwrapped phase change, $\Delta \Phi$, at the last echo time of the dynamic ME-SPGR data. The temperature change $\Delta \mathrm{T}_{\mathrm{n}}$ is related to $\Delta \Phi$ by: $\Delta \mathrm{T}_{\mathrm{n}}=\Delta \Phi / \beta \cdot \gamma \cdot \mathrm{TE} \cdot \mathrm{B}_{0}(10)$, where $\beta$ the temperature dependence water chemical shift of $0.0101 \pm 0.0004 \mathrm{ppm} /{ }^{\circ} \mathrm{C}(17) . \mathrm{PRF}$-based thermometry was corrected for potential $\mathrm{B}_{0}$ drift by using the phase of an agar gel $\left(2 \% \mathrm{w} / \mathrm{w}_{2}{ }^{*} \approx 20 \mathrm{~s}^{-1}\right)$ that was at constant temperature as a reference.

\section{Efficiency assessment of the proposed method}

\section{Sensitivity of signal to $R_{1}$ changes}

The signal change in response to $\mathrm{R}_{1}$-changes was evaluated to assess the sensitivity

of the method. To this end, assuming constant $\mathrm{R}_{2}{ }^{*}$, realistically detectable magnitude signal variations from $-20 \%$ to $20 \%$, were evaluated for different $\mathrm{R}_{1}$ starting values (ranging from 1 to $5 \mathrm{~s}^{-1}$ ). Eq.[4] was solved iteratively to determine the required $\mathrm{R}_{1}$ change. 
Influence of $\Delta R_{2}{ }^{*}$ on $R_{1}$

Eq.[4] implies that there is a correlation between errors in the $\mathrm{R}_{2}{ }^{*}$-change estimate and the estimate of $R_{1}$. For this we may quantify the influence of $\Delta R_{2}{ }^{*}$ as $R_{1}$ can be solved from Eq.[4] (see supplementary material):

$$
\mathrm{R}_{1}=\frac{1}{\mathrm{e}^{\left(\Delta \mathrm{R}_{2}^{*}\right) \mathrm{TE}}} \cdot \frac{\mathrm{Q}_{\mathrm{S}}\left(\frac{\alpha^{2}}{2 \mathrm{TR}}\right)}{\left(1+\frac{\alpha^{2}}{2 \mathrm{R}_{1_{0}} \mathrm{TR}}-\frac{\alpha^{2}}{2}\right)+\mathrm{Q}_{\mathrm{S}}\left(\frac{\alpha^{2}}{2}-1\right)},
$$

from which the partial derivative $\partial \mathrm{R}_{1} / \partial \Delta \mathrm{R}_{2}^{*}$ can then be calculated.

\section{Porcine muscle heating}

A porcine muscle sample of $3 \times 3 \times 1 \mathrm{~cm}^{3}$ was heated from 26 to $34^{\circ} \mathrm{C}$ in a water bath. During heating, real time ME-SPGR images were acquired for 20 minutes. Looklocker based $R_{1}$ maps were calculated before heating and after the sample reached thermal equilibrium in order to validate the real time measurements. The variation of $R_{2}{ }^{*}$ and $R_{1}$ over time were determined in an ROI encompassing the sample. A Luxtron optical probe was placed on top of the sample to monitor temperature (Fig.1b). The temperature dependence of the relaxation rates $\mathrm{R}_{1}$ and $\mathrm{R}_{2}{ }^{*}$ of the porcine muscle sample were determined using weighted linear regression of the relaxation rate to the temperature as measured by the PRFS method.

\section{MR-guided HIFU heating}

Relaxometry and thermometry in the range of mild hyperthermia in porcine muscle tissue were finally demonstrated using a clinical MR-HIFU therapy system (Sonalleve; Philips Healthcare). HIFU heating was performed with an acoustic power of $20 \mathrm{~W}$ for $30 \mathrm{~s}$, starting after $30 \mathrm{~s}$ of scanning which would typicaly lead to a temperature rise of $20^{\circ} \mathrm{C}$. 
Beam-steering of the focused acoustic field was performed to create a 4-mm diameter heating cell (18). The mean and the standard deviation, from a ROI of $4 \times 4$ voxels centered on the heating pattern, were used for monitoring $\mathrm{R}_{1}, \mathrm{R}_{2}{ }^{*}$ and temperature over time. LLbased $R_{1}$ mapping was performed to validate $R_{1}$ values at the end of the procedure. In addition, precision of $\mathrm{R}_{2}{ }^{*}$ and $\mathrm{R}_{1}$ for muscle was estimated before heating in the same region of the sample from the standard deviation over time for the cases when $\Delta \mathrm{B}_{0} / \mathrm{dz}$ was assumed to be 0 , assumed to be constant, or continuously updated, respectively. A fiber optic probe provided the baseline temperature measurement.

\section{Liposome preparation}

Gadolinium-containing thermosensitive liposomes (Gd-TSL) were prepared using the conventional thin-film hydration technique as described previously (19). The TSL formulations consisted of DPPC, DSPC, cholesterol and PEG2000-DSPE in a molar ratio of 67:15:13:5. The lipid concentration was $40 \mathrm{mM}$. The lipid mixture was dissolved in ethanol $(10 \mathrm{~mL})$ and evaporated to dryness by rotary evaporation under vacuum (Rotavapor R-210, BUCHI Laboratory Equipment, Zurich, Switzerland) and the resulting lipid film was further dried under a stream of $\mathrm{N}_{2}$. A solution containing $60 \mathrm{mM}$ of Prohance (gadoteriol, Bracco Diagnostics Inc. NJ, USA) and $10 \mathrm{mM}$ of HEPES Buffered Saline (HBS), containing $135 \mathrm{mM} \mathrm{NaCl}, \mathrm{pH}$ adjusted to 7.4 was used to hydrate the lipid film. The resulting liposome dispersions were sized with sequential extrusion using a Lipex Extruder (Northern Lipids Inc., Vancouver, Canada) and polycarbonate membrane filters (Poretics Corporation, Livermore, CA) with pore diameters of 600, 400 and 200nm. Extra- 
liposomal ProHance was substituted by HBS using PD-10 columns (GE Healthcare, Little Chalfont, UK) for 3 consecutive times.

\section{Liposome characterization}

The average hydrodynamic size and polydispersity index (PDI) of the Gd-TSL was determined with dynamic light scattering (DLS) using a Malvern ALV CGS-3 system (Malvern Instruments Ltd., Worcestershire, United Kingdom).

The chelated Gd concentration was estimated from the measured relaxivity of the free Gd. The $r_{1}$ relaxivity of the chelated gadolinium was calculated from the linear regression of the $\mathrm{R}_{1}$ measured for different concentrations (ranging from 0.1 to $1 \mathrm{mM}$ ). Then the stock $\mathrm{Gd}$ TSL solution was diluted 10 times in 3 samples of $2 \mathrm{ml}$. Each sample was heated for 10 minutes at $45^{\circ} \mathrm{C}$ in presence of Triton $\mathrm{X}-100 . \mathrm{R}_{1}$ was measured for each sample and both the concentration and the encapsulation rate were calculated.

\section{Gd-HPDO3A Release from Thermo-Sensitive Liposomes}

The feasibility to monitor the release of a paramagnetic contrast agent from thermosensitive liposomes (Gd-TSL), using this method was investigated. For that purpose two tubes were placed in a MR compatible water bath and heated from 38.6 to $46^{\circ} \mathrm{C}$ during 20 minutes of scanning. One tube contained $1 \mathrm{~mL}$ of the Gd-TSL preparation diluted 10 times, corresponding to a total $[\mathrm{Gd}]=0.4 \mathrm{mM}$, preheated to $60^{\circ} \mathrm{C}$ for 15 minutes and served as a control. The other contained $1 \mathrm{~mL}$ of fresh Gd-TSL. The variation of the mean and standard deviation of the relaxation times $\mathrm{R}_{1}$ and $\mathrm{R}_{2}{ }^{*}$ and the PRF-based temperature was analyzed using two ROIs of 36 voxels (see Fig.1c). A fiber optic probe in between the tubes provided independent temperature measurement. 


\section{RESULTS}

\section{Sensitivity of signal to $\mathbf{R}_{1}$ changes and influence of $\mathbf{R}_{2}{ }^{*}$ on $\mathbf{R}_{1}$}

The imposed variation of $S_{n} / S_{0}$ and the corresponding resulting $R_{1 n}$ values are shown in Fig.2a. For the scan parameters used in the experiments and for typical $R_{1}(0.8$ to $\left.2.0 \mathrm{~s}^{-1}\right)$, the calculated $\Delta \mathrm{R}_{1}$ is almost directly proportional to the signal variation. Consequently, assuming known $\mathrm{R}_{2}{ }^{*}$, with e.g. $\mathrm{R}_{1}=1 \mathrm{~s}^{-1}\left(\mathrm{~T}_{1}=1000 \mathrm{~ms}\right)$ and a signal change of $\pm 3 \%(\mathrm{SNR} \approx 33)$, the detection limit for $\mathrm{R}_{1}$ changes are around $\pm 0.04 \mathrm{~s}^{-1}( \pm 42 \mathrm{~ms})$.

The partial derivative $\partial \mathrm{R}_{1} / \partial \Delta \mathrm{R}_{2}{ }^{*}$ was calculated (Eq.[5]) for in-vivo typical $\mathrm{R}_{2}{ }^{*}$ values (from 10 to $60 \mathrm{~s}-1=100 \mathrm{~ms}$ ) to quantify the effect of errors in $\mathrm{R}_{2} *$ estimation on the $\mathbf{R}_{1}$ estimation (Fig.2b). On one side, high $\mathbf{R}_{2}{ }^{*}$ values $>50 \mathrm{~s}^{-1}$ lead to high $\partial \mathrm{R}_{1} / \partial \mathrm{R}_{2}{ }^{*}$, implying that such $\mathrm{R}_{2}{ }^{*}$ values have to be accurately measured in order not to corrupt the $\mathrm{R}_{1}$ measurement. In practice, this means that short echo times with short $\Delta \mathrm{TE}$ need to be used. In contrast, errors in measuring relatively low $\mathrm{R}_{2}{ }^{*}$ (under $20 \mathrm{~s}^{-1}$ ) do not affect the R1 estimation substantially; for instance, an error of $1 \mathrm{~s}^{-1}$ for a $\mathrm{R}_{2}{ }^{*}=20 \mathrm{~s}^{-1}$, would translate into an error of $0.01 \mathrm{~s}^{-1}$ in $\Delta \mathrm{R}_{1}$.

\section{Porcine muscle heating}

The water bath study was performed to validate the real-time $\mathrm{R}_{1}$ measurements (Fig.3). The mean values of the LL-based $\mathrm{R}_{1}$ measurements were $1.26 \pm 0.04 \mathrm{~s}^{-1}$ and $1.17 \pm$ $0.04 \mathrm{~s}^{-1}$ at $26^{\circ} \mathrm{C}$ and at the thermal equilibrium of $34^{\circ} \mathrm{C}$, respectively. With an SNR of 38 on the first echo of the ME-SPGR data, the near real time $\mathrm{R}_{1}$ measurement after heating was $1.18 \pm 0.07 \mathrm{~s}^{-1}$ and showed a good correspondence to the LL-based $\mathrm{R}_{1}$ measurement. $\mathrm{R}_{1}$ 
was found to decrease with a temperature dependence of $-0.0161 \pm 0.0005 \mathrm{~s}^{-1} .{ }^{\circ} \mathrm{C}^{-1}$ which corresponds to a change in $\mathrm{T}_{1}$ of $1.31 \pm 0.05 \% .{ }^{\circ} \mathrm{C}^{-1}$.

The value of $\mathrm{R}_{2}{ }^{*}$, when $\Delta \mathrm{B}_{0 / \mathrm{dz}}$ was assumed to be constant, was on average $0.92 \pm$ $0.16 \mathrm{~s}^{-1}$ lower than if $\Delta \mathrm{B}_{0} / \mathrm{dz}$ was assumed to be zero, confirming the contribution of the field gradient to $\mathrm{R}_{2}{ }^{*}$.(Fig. 3b). However, without $\Delta \mathrm{B}_{0} / \mathrm{dz}$ compensation, the measured value was more precise, with a standard deviation of $0.28 \pm 0.17 \mathrm{~s}^{-1}$ vs $0.66 \pm 0.21 \mathrm{~s}^{-1}$ with compensation. The computation time of the $\mathrm{R}_{1}$ map, the $\mathrm{R}_{2}{ }^{*}$ map and the temperature map was under $0.8 \mathrm{~s}$ per frame allowing for near-real-time monitoring.

\section{MR-guided HIFU heating}

The areas with $\mathrm{R}_{1}$ and $\mathrm{R}_{2}{ }^{*}$ changes, and the heated area based on the PRF values showed a good correspondence in position and shape (Fig.4 and Table 1). When taking into account APD changes with temperature, the bias in $\mathrm{R}_{1}$ was essentially removed. The precision of $R_{1}$ was essentially independent of the way $R_{2}{ }^{*}$ was calculated, which may be related to the high SNR of 85 in this experiment, as well as the moderate $\mathrm{R}_{2}$ of muscle. Nevertheless, iteratively updating $\Delta \mathrm{B}_{0} / \mathrm{dz}$ led to a higher variance in the $\mathrm{R}_{2}{ }^{*}$ estimates than assuming constant or zero $\Delta \mathrm{B}_{0} / \mathrm{dz}$. PRF-based temperature precision was $0.37 \pm 0.2^{\circ} \mathrm{C}$. The HIFU heating of 30 seconds caused a temperature increase of $20^{\circ} \mathrm{C}$. Both, $\mathrm{R}_{2}{ }^{*}$ and the susceptibility corrected $\mathrm{R}_{2}{ }^{*}$ increased during the heating period and decreased during the cooling process. The final $\mathrm{R}_{1}$ measurement from the Look-Locker, corresponded well to the last incrementally calculated $\mathrm{R}_{1}$ determined from the dynamic series. Similar temperature dependence as measured in the water bath experiment were found for muscle: $-0.0127 \pm$ $0.0003 \mathrm{~s}^{-1} \cdot{ }^{\circ} \mathrm{C}^{-1}$ and $0.35 \pm 0.01 \mathrm{~s}^{-1} .{ }^{\circ} \mathrm{C}^{-1}$ for $\mathrm{R}_{1}$ and $\mathrm{R}_{2}{ }^{*}$, respectively. 


\section{Gd-HPDO3A loaded temperature-sensitive liposomes}

Gd-TSL encapsulating $60 \mathrm{mM}[\mathrm{Gd}(\mathrm{HPDO} 3 \mathrm{~A})(\mathrm{H} 2 \mathrm{O})]$ were prepared using the lipid film hydration technique followed by sequential extrusion. The hydrodynamic diameter of the Gd-TSLs was $194 \pm 18 \mathrm{~nm}$ with a corresponding PDI of 0.04 . The melting phase transition temperature was $42.2{ }^{\circ} \mathrm{C}$ with a DSC peak maximum of $44.3{ }^{\circ} \mathrm{C}$. The $\mathrm{R}_{1}$ relaxation rate of the released gadolinium from the 10 times diluted stock Gd-TSL was on average equal to $3.1 \pm 0.1 \mathrm{~s}^{-1}$ corresponding to a concentration of $4.0 \pm 0.2 \mathrm{mM}$ of the stock solution and an encapsulation rate of $6.6 \%$.

\section{Gd-HPDO3A Release from Thermo-Sensitive Liposomes}

Finally, it was demonstrated that the proposed method can be used to monitor the release of a Gd-chelate from TSLs during a water bath heating experiment (Fig.5). The need for the APD correction was underlined by the comparison of the $\mathrm{R}_{1}$ calculated from the ME-SPGR data during heating, $2.01 \pm 0.10 \mathrm{~s}^{-1}$ with vs $1.93 \pm 0.11 \mathrm{~s}^{-1}$ without APD correction, and the Look Locker data acquired at the end, $1.99 \pm 0.06 \mathrm{~s}-1$. PRF-based thermometry from the TSL tube and the fiber optic thermometer measurements showed an $\mathrm{r}^{2}$ coefficient of 0.98 , validating the temperature measurements using this method.

For the freshly prepared Gd-TSL, a positive $\mathrm{R}_{1}$ variation was observed from $38.6^{\circ} \mathrm{C}$ to $42^{\circ} \mathrm{C}$ $\left(\mathrm{t}=11 \mathrm{~min}\right.$ ). During the phase transition, from $42.2^{\circ} \mathrm{C}$ to $44^{\circ} \mathrm{C}$, a sigmoidal-like increase of $\mathrm{R}_{1}$ was measured. Above the phase transition, $\mathrm{R}_{1}$ values were similar to these of the preheated Gd-TSL control sample until the end of the experiment. The control sample presented a small negative temperature dependence, during the whole heating process. 
Corresponding $\mathrm{R}_{2}{ }^{*}$ measurements (Fig. 5e,f) a detecteble but small change was found upon release, which is probably related to the limited $\mathrm{R}_{2}{ }^{*}$ effect of chelated Gd. 


\section{DISCUSSION}

In this study, it has been shown that $\mathrm{R}_{1}, \mathrm{R}_{2}{ }^{*}$ and temperature can be monitored based on a multi-echo SPGR sequence.

The ability of a $\mathrm{T}_{2}{ }^{*}$ shortening agent to create contrast even when encapsulated into nanoparticles $(6,20-22)$, makes $\mathrm{R}_{2}{ }^{*}$ an interesting mechanism for monitoring the availability of drug-nanocarriers in the tissue. In addition, earlier studies using thermosensitive liposomes have shown the potential of MRI to monitor the release from nanocarriers using $\mathrm{R}_{1}$ mapping $(8,23,24)$. Dahnke et al. showed that for slice selective multi-echo sequences $\mathrm{R}_{2}{ }^{*}$ has to be compensated for $\mathrm{B}_{0}$ gradients in slice direction (14). In our case, $\Delta \mathrm{B}_{0} / \mathrm{dz}$ was weak and stable for temperatures in the mild hyperthermia range up to $43^{\circ} \mathrm{C}$. However, as demonstrated in this paper, $\mathrm{R}_{2}{ }^{*}$ changes need to be estimated accurately and precisely to allow for $\mathrm{R}_{1}$ monitoring based on signal changes. In this study, three ways of handling $\mathrm{B}_{0}$ in $\mathrm{R}_{2}{ }^{*}$ estimation have been compared, and it was confirmed that including $\Delta \mathrm{B}_{0} / \mathrm{dz}$ in the $\mathrm{R}_{2}{ }^{*}$ estimation removes biases. Nevertheless, it may be advantageous to measure $\Delta \mathrm{B}_{0} / \mathrm{dz}$ once and then keep it fixed, rather than to update it over time. Firstly, this allows using a single slice sequence for the dynamic $\mathrm{R}_{2}{ }^{*}$ measurement. Secondly, in situations with low SNR, attempts to fit $\Delta \mathrm{B}_{0} / \mathrm{dz}$ from the signal magnitude evolution with $\mathrm{TE}$ in a single slice for each dynamic will increase the variance on the $\mathrm{R}_{2}{ }^{*}$ estimate, which may cross over to the $\mathrm{R}_{1}$ estimates as well.

The PRF-based temperature measurements in turn allowed correcting APD changes in the $\mathrm{R}_{1}$ estimate during heating. Obeying the Boltzmann distribution, the dependence of APD on temperature is well-known, and within the examined temperature range effectively allowed 
for correction of the bias that was present without taking APD changes into account in the Gd-TSL release experiments. However, this method requires a reference $\mathrm{R}_{1}$ map to allow calculating absolute $R_{1}$ values from the magnitude signal changes, as well as a phase reference for the temperature updates. This introduces motion sensitivity, and may thus limit its applications as this method will suffer from the defects as the PRF method.

Moreover, Hijnen et al. have shown that change of $\mathrm{Gd}$ concentration biases the PRF thermometry mostly due to changes of bulk magnetic susceptibilities (25) similarly to the motion sensitivity of the PRFS method that is based on phase subtraction. By monitoring $\mathrm{R}_{2}{ }^{*}$ over time, we may detect when the $\mathrm{Gd}$ concentration is stable, and then initiate the heating under control of thermometry.

With respect to the microscopic local field inhomogeneities, the $\mathrm{R}_{2}{ }^{*}$ changes, albeit weak, (Fig. 5e,f) and did not exclude accurate PRF-thermometry and $\mathrm{R}_{1}$ measurement.

Measured $R_{1}$ temperature dependences of ex vivo porcine muscle were found to be independent of the heating device (HIFU vs water bath heating). Comparable $\mathrm{T}_{1}$ temperature dependence , $1.4 \pm 0.2 \% .{ }^{\circ} \mathrm{C}^{-1}$, were found in literature (26) even if such values are highly dependent on measurement technique and tissue composition (27). The computation time was substantially smaller than the heating and release processes, as well as the dynamic scan time of the multi-echo SPGR sequence and thus suited for near-realtime monitoring.

Properly quantifying the released fraction of a contrast agent from thermosensitive nanocarriers looking at $\mathrm{R}_{1}$ variations is difficult. Indeed, these variations also reflect the temperature and the concentration changes which are tissue dependent. However, looking 
to $\mathrm{R}_{2}{ }^{*}$ variation should allow us to look not only to the $\Delta \mathrm{R}_{1}$ but also to the ratio $\Delta \mathrm{R}_{2}{ }^{*} / \Delta \mathrm{R}_{1}$ as proposed by Terreno et al. to measure e.g. pH using Gadolinium complexes (28). 


\section{CONCLUSION}

We presented and validated a method for simultaneous PRF-based thermometry, and $\mathrm{R}_{1}$ and $\mathrm{R}_{2}{ }^{*}$ mapping with a spatial and temporal resolution high enough to characterize the release of contrast agents from TSL and to monitor HIFU heating, with potential for application in MRI-guided drug delivery studies. Computation time was $<0.05 \mathrm{~ms}$ voxel ${ }^{-1}$ witch allow for a complet mapping of a FOV equal to $128 \times 128$ in less than a second.

\section{ACKNOWLEDGEMENTS}

This work was supported by the Sound Pharma project (funded by the European Research Council). We would like to extend our profound and warmest thanks to the regretted Dr. Pierre Smirnov without whom this work would not have been possible. 


\section{REFERENCES}

1. Allen TM, Cullis PR. Drug Delivery Systems: Entering the Mainstream. Sci. 2004;303(5665):1818-1822. DOI: 10.1126/science.1095833

2. Xie J, Lee S, Chen X. Nanoparticle-based theranostic agents. Adv Drug Deliv Rev. 2010;62(11):1064-1079. DOI: 10.1016/j.addr.2010.07.009

3. Lammers T, Aime S, Hennink WE, Storm G, Kiessling F. Theranostic Nanomedicine. Acc Chem Res. 2011;44(10):1029-1038. DOI: 10.1021/ar200019c

4. Kelkar SS, Reineke TM. Theranostics: Combining Imaging and Therapy. Bioconjugate Chem. 2011;22(10):1879-1903. DOI: 10.1021/bc200151q

5. Terreno E, Delli Castelli D, Cabella C, Dastrù W, Sanino A, Stancanello J, Tei L, Aime S. Paramagnetic liposomes as innovative contrast agents for magnetic resonance (MR) molecular imaging applications. Chem Biodivers. 2008;5(10):1901-1912. DOI: 10.1002/cbdv.200890178

6. Lorenzato C, Cernicanu A, Meyre M-E, Germain M, Pottier A, Levy L, de Senneville BD, Bos C, Moonen C, Smirnov P. MRI contrast variation of thermosensitive magnetoliposomes triggered by focused ultrasound: a tool for image-guided local drug delivery. Contrast Media Mol Imaging. 2013;8(2):185-192. DOI: 10.1002/cmmi.1515

7. Fossheim SL, Il'yasov KA, Hennig J, Bjørnerud A. Thermosensitive paramagnetic liposomes for temperature control during MR imaging-guided hyperthermia: In vitro feasibility studies. Acad Radiol. 2000;7(12):1107-1115. DOI: 10.1016/S10766332(00)80064-1

8. De Smet M, Langereis $\mathrm{S}$, den Bosch $\mathrm{S}$ van, Grüll H. Temperature-sensitive liposomes for doxorubicin delivery under MRI guidance. J Con Rel. 2010;143(1):120-127. DOI: 10.1016/j.jconrel.2009.12.002

9. De Zwart JA, Salomir R, Vimeux F, Klaveness J, Moonen CTW. On the feasibility of local drug delivery using thermo-sensitive liposomes and MR-guided focused ultrasound. In: Denver 8th ISMRM; 2000.

10. Poorter JD, Wagter CD, Deene YD, Thomsen C, Ståhlberg F, Achten E. Noninvasive MRI Thermometry with the Proton Resonance Frequency (PRF) Method: In Vivo Results in Human Muscle. Magn Reson Med. 1995;33(1):74-81. DOI: 10.1002/mrm.1910330111

11. Quesson B, de Zwart JA, Moonen CTW. Magnetic resonance temperature imaging for guidance of thermotherapy. J Magn Reson Im. 2000;12(4):525-533. DOI: 10.1002/1522-2586(200010)12:4<525::AID-JMRI3>3.0.CO;2-V

12. Deckers R, Moonen CTW. Ultrasound triggered, image guided, local drug delivery. J Con Rel. 2010;148(1):25-33. DOI: 10.1016/j.jconrel.2010.07.117

13. Bos C, Lepetit-Coiffé M, Quesson B, Moonen CTW. Simultaneous monitoring of temperature and T1: Methods and preliminary results of application to drug delivery using thermosensitive liposomes. Magn Reson Med. 2005;54(4):1020-1024. DOI: 10.1002/mrm.20635

14. Dahnke H, Schaeffter T. Limits of detection of SPIO at 3.0 T using T2* relaxometry. Magn Reson Med. 2005;53(5):1202-1206. DOI: 10.1002/mrm.20435 
15. Look DC, Locker DR. Time Saving in Measurement of NMR and EPR Relaxation Times. Rev of Sci Instr. 1970;41(2):250-251. DOI: doi:10.1063/1.1684482

16. Chen J, Daniel BL, Pauly KB. Investigation of proton density for measuring tissue temperature. J Magn Reson Im. 2006;23(3):430-434. DOI: 10.1002/jmri.20516

17. Peters RTD, Hinks RS, Henkelman RM. Ex vivo tissue-type independence in protonresonance frequency shift MR thermometry. Magn Reson Med. 1998;40(3):454-459. DOI: $10.1002 / \mathrm{mrm} .1910400316$

18. Partanen A, Tillander M, Yarmolenko PS, Wood BJ, Dreher MR, Kohler MO. Reduction of peak acoustic pressure and shaping of heated region by use of multifoci sonications in MR-guided high-intensity focused ultrasound mediated mild hyperthermia. Med Phys. 2013;40(1):013301. DOI: 10.1118/1.4769116

19. Koning GA, Morselt HWM, Velinova MJ, Donga J, Gorter A, Allen TM, Zalipsky S, Kamps JAAM, Scherphof GL. Selective transfer of a lipophilic prodrug of 5fluorodeoxyuridine from immunoliposomes to colon cancer cells. Biochimica et Biophysica Acta (BBA) - Biomembranes. 1999;1420(1-2):153-167. DOI: 10.1016/S0005-2736(99)00091-7

20. Bulte JW, De Cuyper M. Magnetoliposomes as contrast agents. Meth Enzymol. 2003;373:175-198.

21. Girard OM, Ramirez R, McCarty S, Mattrey RF. Toward absolute quantification of iron oxide nanoparticles as well as cell internalized fraction using multiparametric MRI. Contrast Media Mol Imagnig. 2012;7(4):411-417. DOI: 10.1002/cmmi.1467

22. Billotey C, Wilhelm C, Devaud M, Bacri J c., Bittoun J, Gazeau F. Cell internalization of anionic maghemite nanoparticles: Quantitative effect on magnetic resonance imaging. Magn Reson Med. 2003;49(4):646-654. DOI: 10.1002/mrm.10418

23. Viglianti BL, Ponce AM, Michelich CR, Yu D, Abraham SA, Sanders L, Yarmolenko PS, Schroeder T, MacFall JR, Barboriak DP, Colvin OM, Bally MB, et al. Chemodosimetry of in vivo tumor liposomal drug concentration using MRI. Magn Reson Med. 2006;56(5):1011-1018. DOI: 10.1002/mrm.21032

24. Ponce AM, Viglianti BL, Yu D, Yarmolenko PS, Michelich CR, Woo J, Bally MB, Dewhirst MW. Magnetic resonance imaging of temperature-sensitive liposome release: drug dose painting and antitumor effects. J Natl Cancer Inst. 2007;99(1):5363. DOI: 10.1093/jnci/djk005

25. Hijnen NM, Elevelt A, Pikkemaat J, Bos C, Bartels LW, Grüll H. The magnetic susceptibility effect of gadolinium-based contrast agents on PRFS-based MR thermometry during thermal interventions. $\mathbf{J}$ Ther Ultrasound. 2013;1(1):8. DOI: 10.1186/2050-5736-1-8

26. Cline HE, Hynynen K, Hardy CJ, Watkins RD, Schenck JF, Jolesz FA. MR temperature mapping of focused ultrasound surgery. Magn Reson Med. 1994;31(6):628-636.

27. Bottomley PA, Foster TH, Argersinger RE, Pfeifer LM. A review of normal tissue hydrogen NMR relaxation times and relaxation mechanisms from 1-100 MHz: dependence on tissue type, NMR frequency, temperature, species, excision, and age. Med Phys. 1984;11(4):425-448. 
28. Aime S, Fedeli F, Sanino A, Terreno E. A R2/R1 ratiometric procedure for a concentration-independent, pH-responsive, Gd(III)-based MRI agent. J Am Chem Soc. 2006;128(35):11326-11327. DOI: 10.1021/ja062387x 


\section{Table}

Table 1: Comparison of ending $\mathrm{R}_{1}$ values and the Look Locker measurements from the HIFU experiment

\begin{tabular}{|c|c|c|c|c|c|c|}
\hline $\begin{array}{l}\text { Handling of } \\
\qquad \Delta \mathbf{B}_{0 / \mathrm{d} z}\end{array}$ & $\begin{array}{c}\text { Ending } R_{1} \text { [s } \\
1 \\
] \\
M_{0}^{-}= \\
\text {constant }\end{array}$ & Bias $^{a}$ & $\begin{array}{c}\text { Ending } R_{1}\left[\mathrm{~s}^{-1}\right] \\
M_{0}(\text { Temperature })\end{array}$ & $\operatorname{Bias}^{b}$ & $\begin{array}{c}\mathbf{R}_{1} \text { Precision }^{\mathrm{c}} \\
{\left[\mathrm{s}^{-1}\right]}\end{array}$ & $\begin{array}{c}\mathbf{R}_{2}^{*} \\
\text { Precision } \\
{\left[\mathbf{s}^{-1}\right]}\end{array}$ \\
\hline$\Delta \mathrm{B}_{0} / \mathrm{dz}=0$ & $1.538 \pm 0.081$ & -0.0072 & $1.548 \pm 0.08$ & 0.0025 & $0.039 \pm 0.007$ & $\begin{array}{c}0.725 \pm \\
0.170\end{array}$ \\
\hline$\Delta \mathrm{B}_{0} / \mathrm{dz}$ constant & $1.536 \pm 0.082$ & -0.0079 & $1.547 \pm 0.08$ & -0.0003 & $0.039 \pm 0.007$ & $\begin{array}{c}0.724 \pm \\
0.168\end{array}$ \\
\hline$\Delta \mathrm{B}_{0} / \mathrm{dz}$ updated & $1.538 \pm 0.082$ & -0.0077 & $1.55 \pm 0.08$ & 0.0003 & $0.042 \pm 0.008$ & $\begin{array}{c}0.863 \pm \\
0.198\end{array}$ \\
\hline
\end{tabular}

${ }^{\mathrm{a}}$ Bias = ending $\mathrm{R}_{1}$ with $\mathrm{M}_{0}$ constant - Look Locker $\mathrm{R}_{1}$ measurement. ${ }^{\mathrm{b}}$ Bias $=$ final $\mathrm{R}_{1}$ with $\mathrm{M}_{0}(\mathrm{~T})-$ Look Locker final $\mathrm{R}_{1}$ measurement. ${ }^{\mathrm{c}}$ Temporal standard deviation before heating. 


\section{Figure captions}
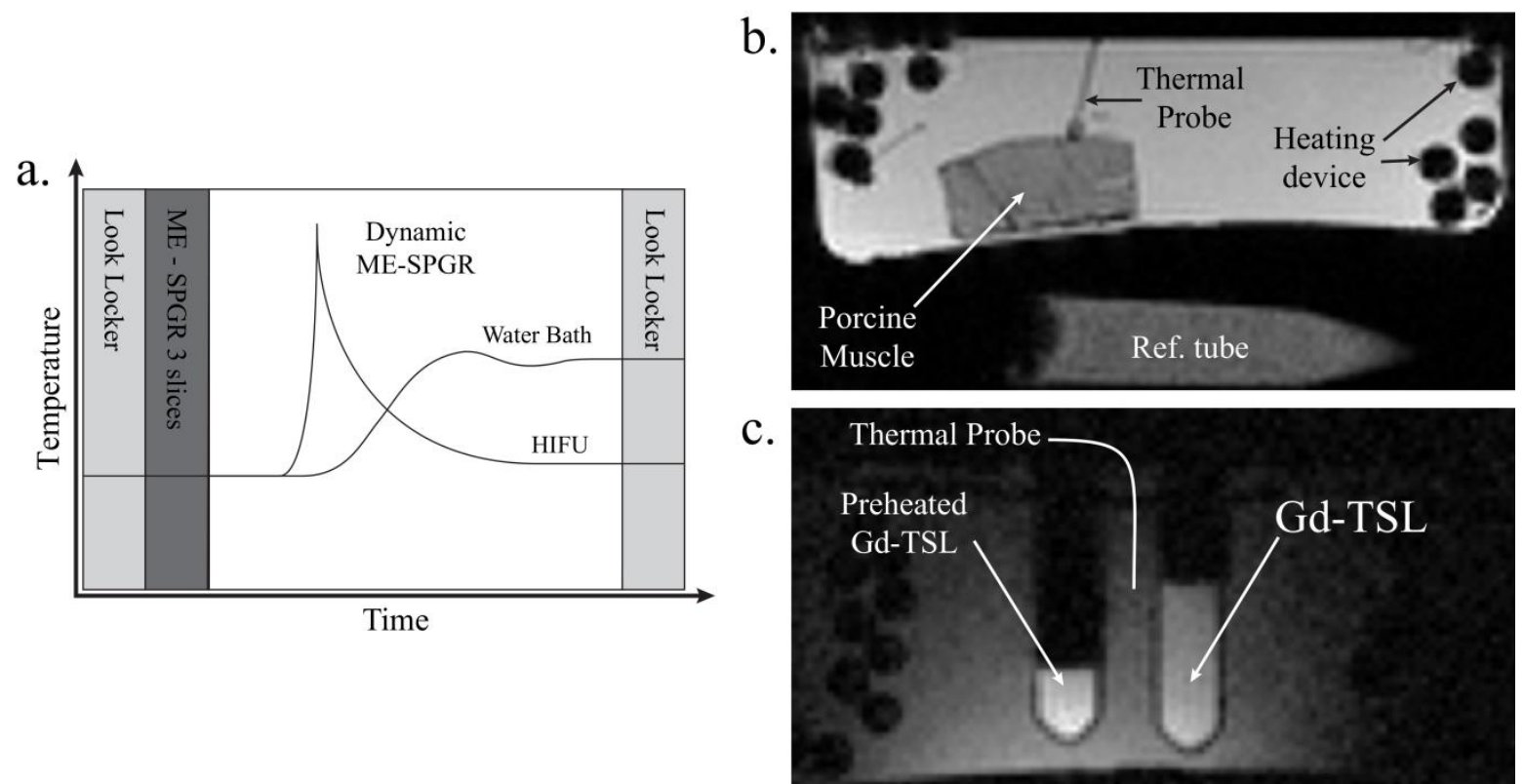

Figure 1: Schematic of MR scanning protocol (a) with the corresponding temperature vs. time profile for the water bath and the HIFU heating studies. Magnitude images of the experimental setup for water bath heating of the porcine muscle sample (b) and the TSL (c). 

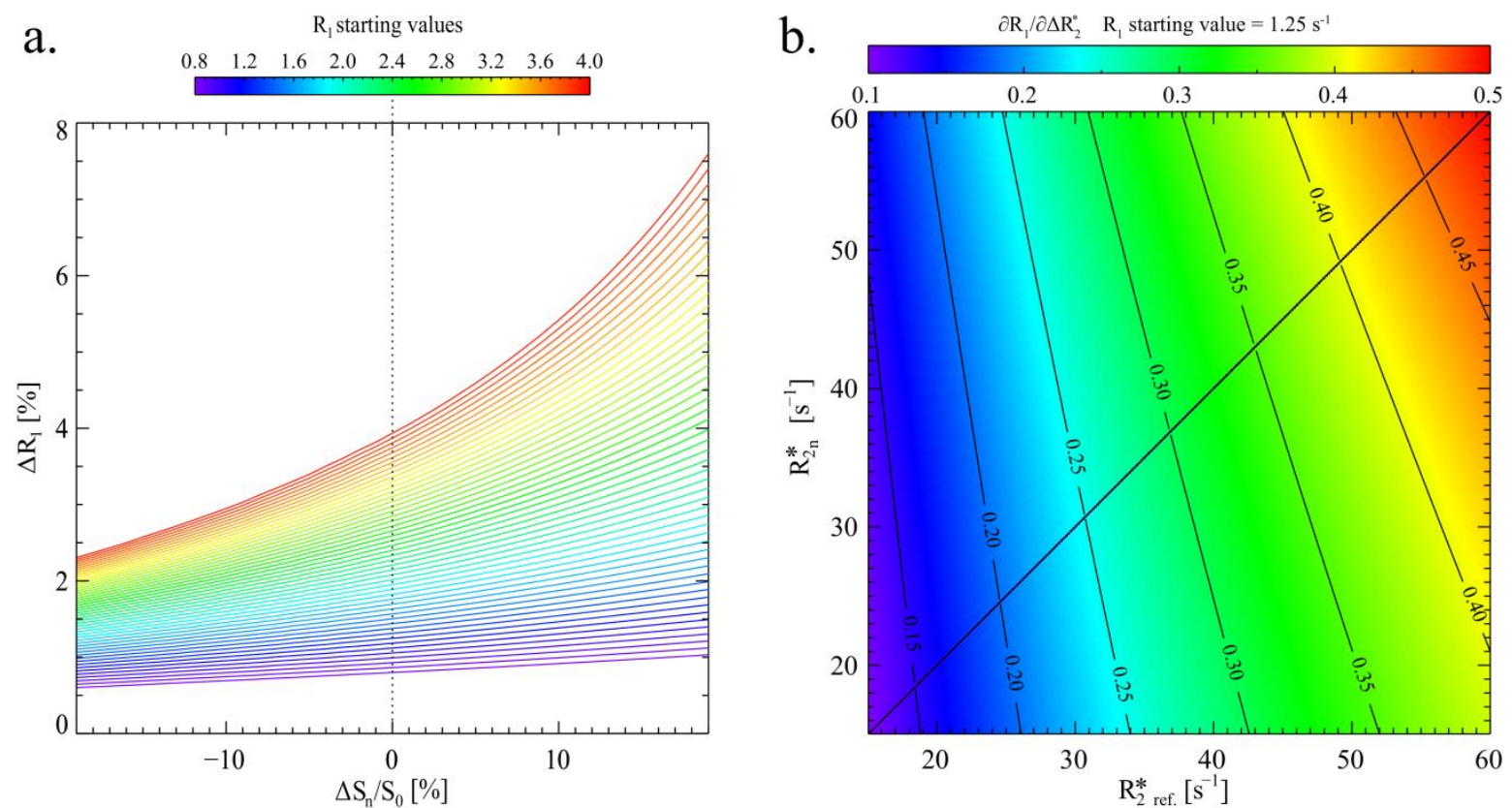

Figure 2: Simulated magnitude signal variation $\Delta \mathrm{Sn} / \mathrm{S} 0$ and the corresponding increase/decrease of $\mathrm{R} 1$ for different $\mathrm{R}_{1}$ starting values (color-coded scale) (a). Influence of uncertainties in the estimation of $R_{2}{ }^{*}$ change on the $R_{1}$ estimation (b), for an example starting value of $R_{1}=1.25 \mathrm{~s}-1$, expressed as the partial derivative $\partial R_{1} / \partial \Delta R_{2}{ }^{*}$ for a $T R=50$ $\mathrm{ms}, \mathrm{TE}=4.6 \mathrm{~ms}$ 

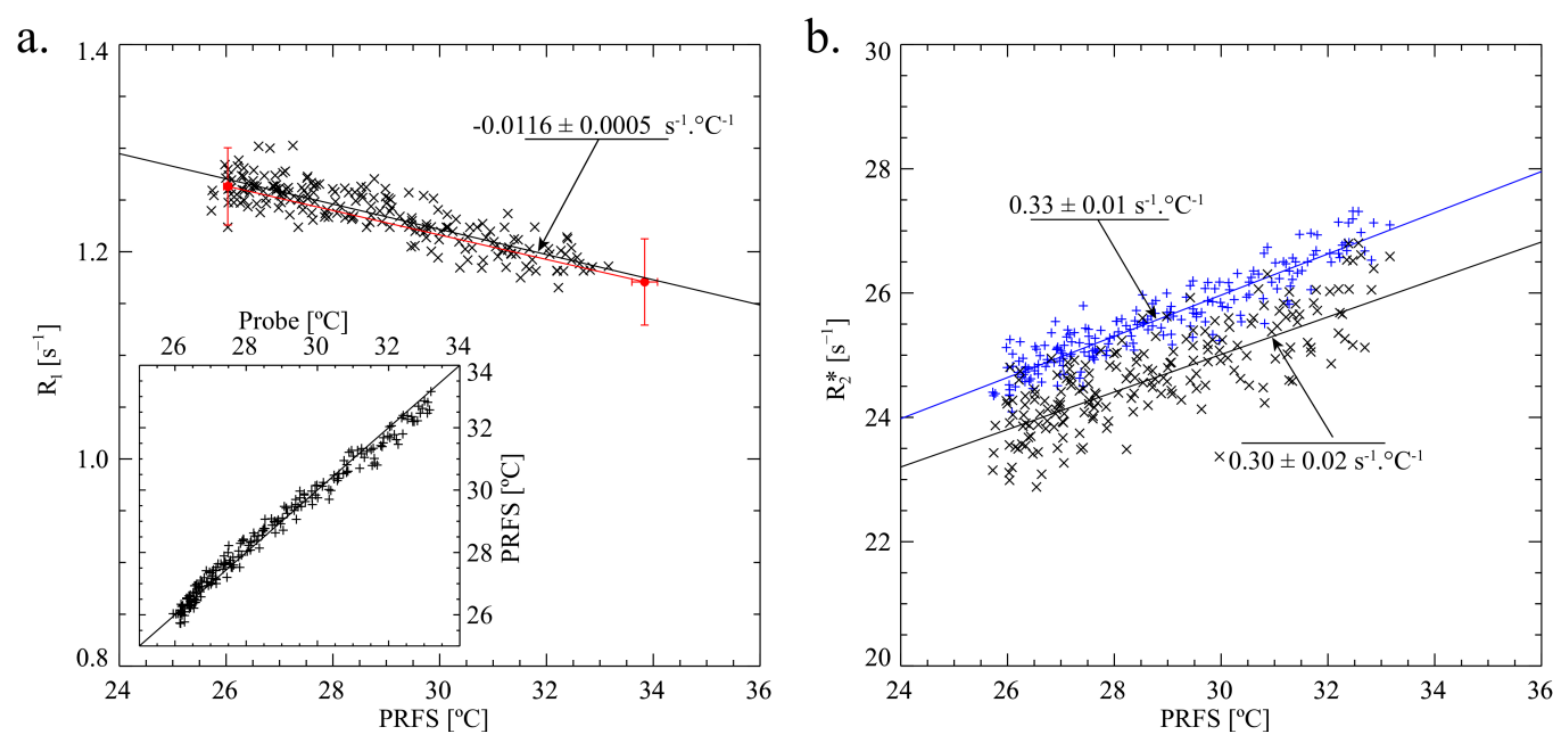

Figure 3: Near real-time $\mathrm{R}_{1}$ variation of muscle as a function of PRF thermometry during water bath heating (a). The inset shows a comparison between MR-thermometry and the optical temperature probe. The values of the LL-based measurements at $26^{\circ} \mathrm{C}$ and at $34^{\circ} \mathrm{C}$ are plotted in red. $\mathrm{R}_{2}{ }^{*}$ measurement as a function of temperature (b), with sinus cardinal correction updated $(\mathbf{x})$ and without $(+)$. 
a.
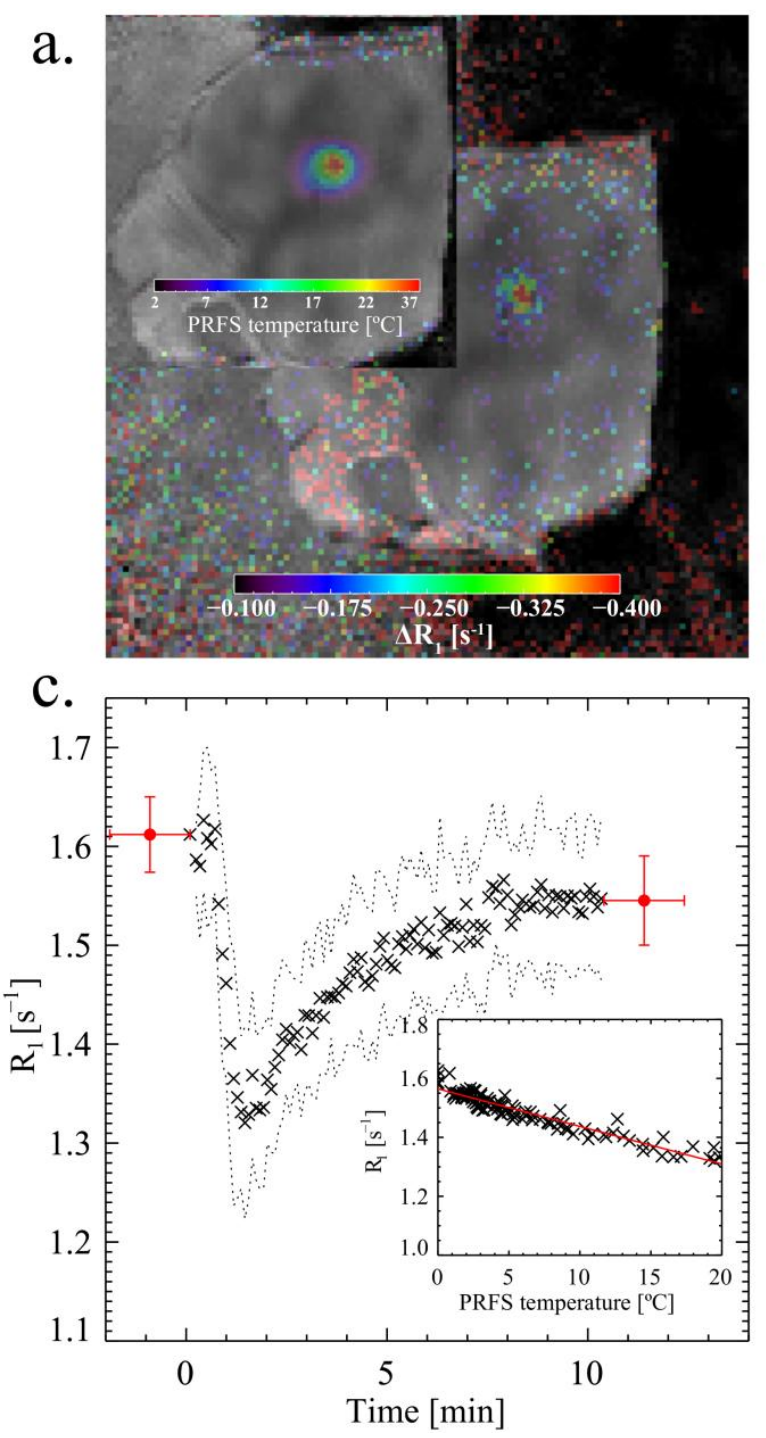

b.

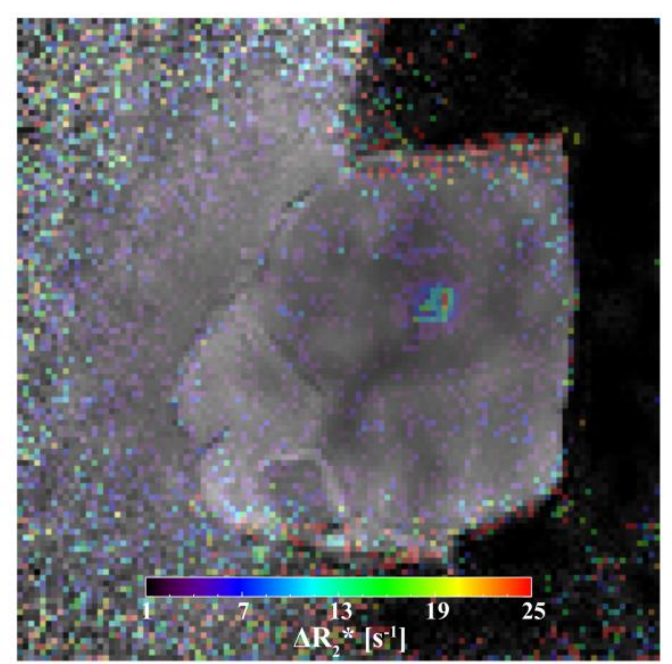

d.

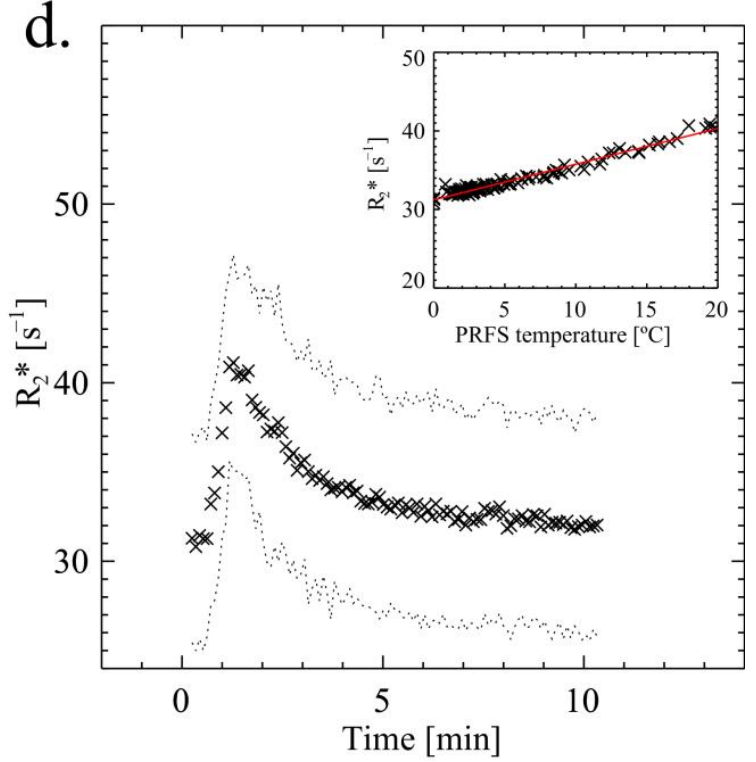

Figure 4: Dynamic magnitude image measured at 1.5 minutes with $\Delta \mathrm{R}_{1}$ overlay (a) and $\Delta \mathrm{R}_{2}{ }^{*}$ overlay (b). The inset in (a) shows PRF thermometry data. Evolution over time of $\mathrm{R}_{1}$ (c) and $\mathrm{R}_{2}{ }^{*}$ (d), respectively, measured at the focal point $\left(4 \times 4 \mathrm{~mm}^{2}\right)$ during the HIFU heating applied from 0.5 to $1 \mathrm{~min}$. 

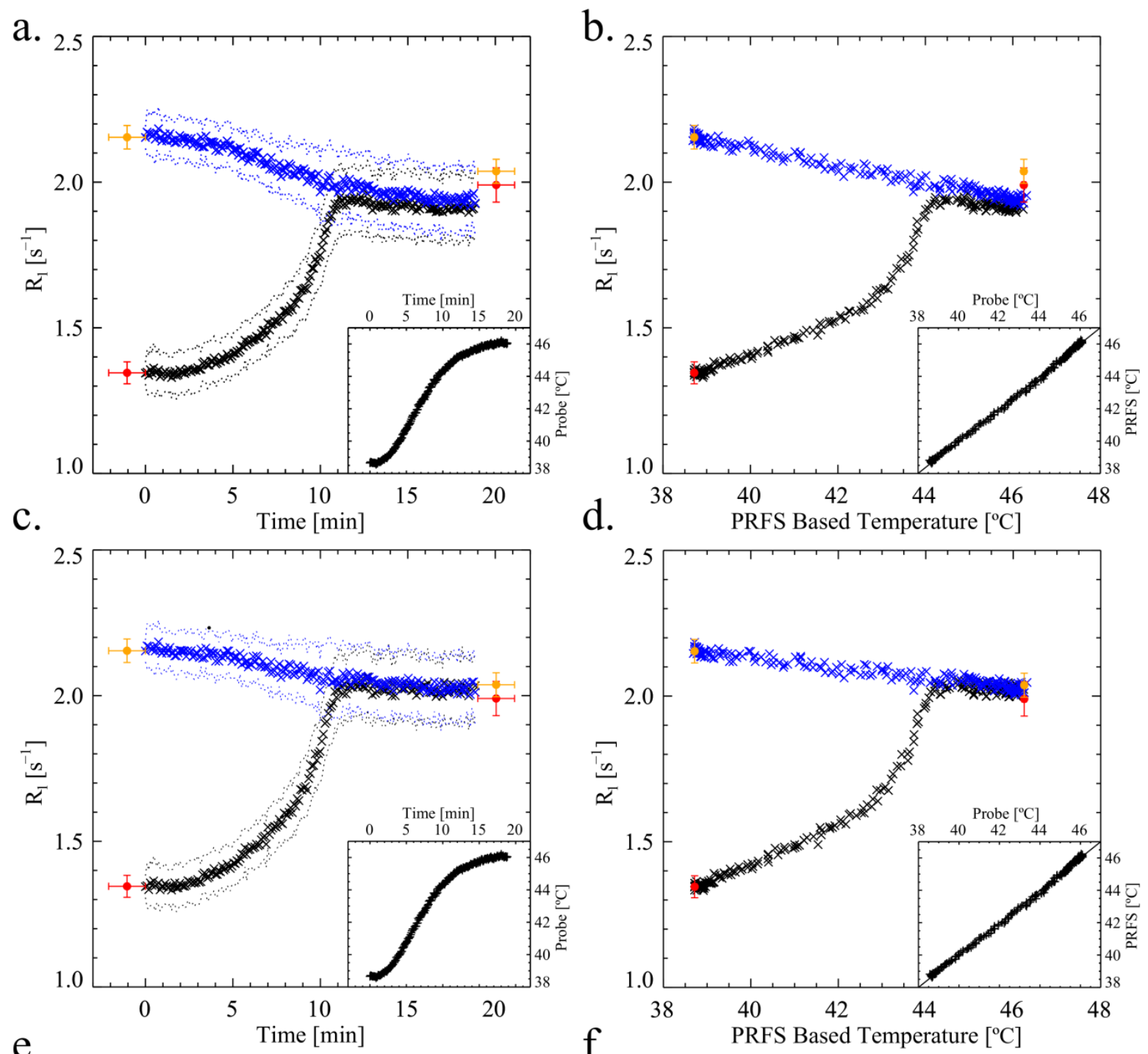

e.
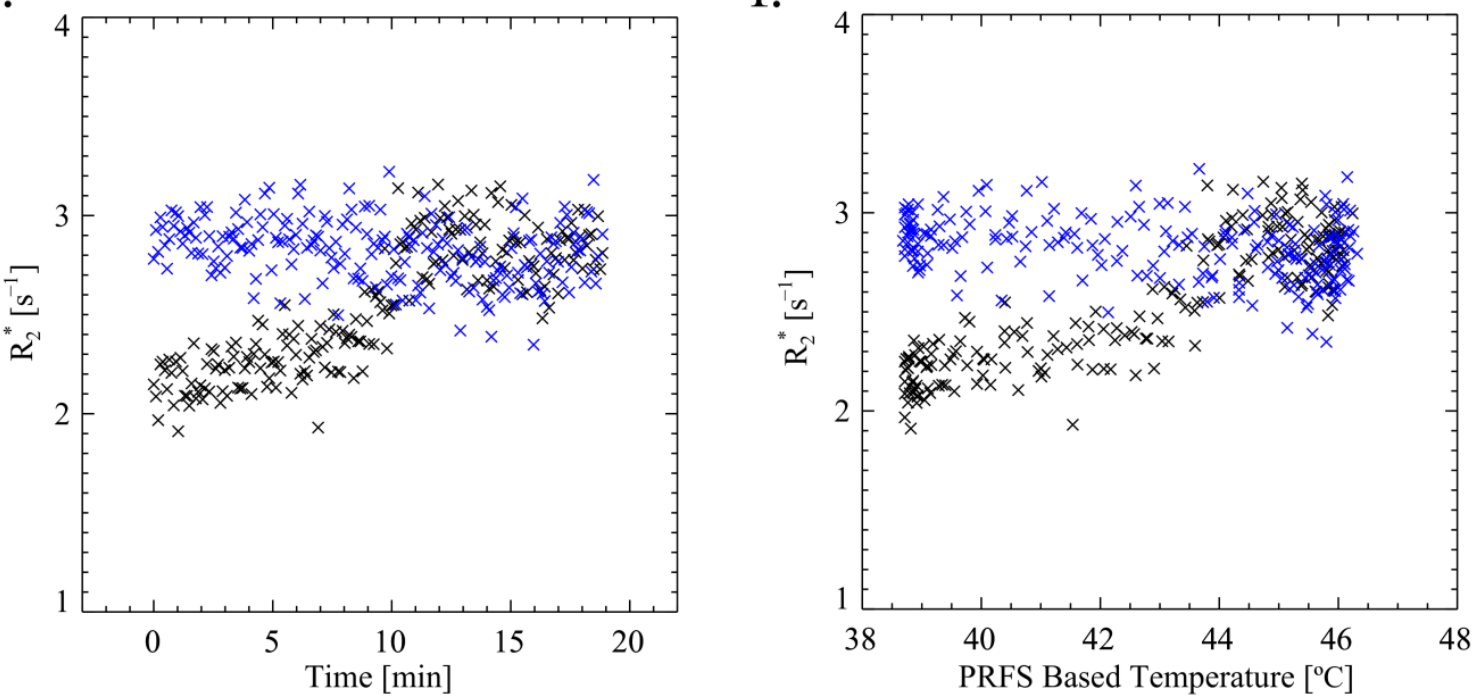
Figure 5: Scatterplot of the uncorrected (a. b.) and APD corrected (c. d.) dynamic $\mathrm{R}_{1}$ measurements versus time (a. c.) and temperature (b. d.) of the TSL (black $\mathbf{x}$ ) and preheated TSL (blue $x$ ). Insets show the probe temperature vs. time and the probe temperature vs. the PRF-based temperature. $\mathrm{R}_{1}$ measurements from the Look Locker of TSL (red) and the control tubes (orange) are plotted for comparison with near real time data. Corresponding dynamic $\Delta \mathrm{B}_{0} / \mathrm{dz}$ corrected $\mathrm{R}_{2}{ }^{*}$ measurements versus time (a.) and temperature (b.). 